\title{
Study on Safety Quality Training Index System of Air Force Aviation Crew
}

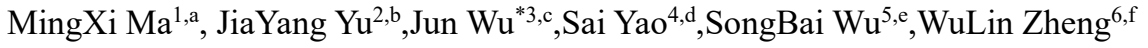 \\ ${ }^{1}$ Air Traffic Control and Navigation College Air Force Engineering University Xi'an, China \\ ${ }^{2}$ Equipment Management and UAV Engineering College Air Force Engineering University Xi'an, China \\ ${ }^{3}$ Air Traffic Control and Navigation College Air Force Engineering University Xi'an, China \\ ${ }^{4}$ Equipment Management and UAV Engineering College Air Force Engineering University Xi'an, China \\ ${ }^{5}$ Unit 95118 DangYang, China \\ ${ }^{6}$ Department of Basic Sciences Air Force Engineering University Xi'an, China
}

\begin{abstract}
In the new era of Air Force equipment upgrading with times, in view of the air crew safety quality growing impact on the aviation flight safety, this paper, based on a large number of data, investigates the basic situation of the safety quality of the maintenance personnel by using the questionnaire survey method, analyzes the reliability of the questionnaire content by using SPSSAU system, summarizes the components of the safety quality of the maintenance personnel according to the feedback results of the questionnaire, and divides the training indicators; then the Delphi method and analytic hierarchy process are used to calculate the weight of each training index of the safety quality of the maintenance personnel. Finally, the training index system of the safety quality of the maintenance personnel is established, and some suggestions are given for the assessment and improvement of the safety quality of the maintenance personnel.
\end{abstract}

\section{INTRODUCTION}

Under the background of the new era that the weapons and equipment of the Air Force are becoming more and more scientific and technological, the war is becoming more and more modernized and informationized, and the reform of army is being carried out intensively, the pressure of aviation maintenance work is increasing sharply, and safety accidents occur from time to time. As the main undertakers of aircraft maintenance work, aviation maintenance personnel not only shoulder the task of protecting the security of motherland's property, but also bear the responsibility of protecting the lives of comrades in arms. This requires the maintenance personnel to have rich work experience and high level of safety quality.

Literature [1] from the pressure of pilot, through combing the flight personnel of work pressure, work pressure source related theory, such as preparation of the present situation of pilot work stress questionnaire, using the working pressure source model from the psychological quality of classical theory, flight mission pilot work stress problem is discussed, the civil aviation flight stress management system is put forward; literature [2] starts from the factors affecting the safety behavior of aviation crew, analyzes the psychological factors, safety attitudes, social opinions and other aspects, and obtains the training methods for the safety behavior of flight crew, which lays a foundation for improving the safety ability of flight crew. For literature [3], in order to reduce the unsafe events caused by the poor psychological quality of aviation safety officers, the necessary psychological quality indexes of qualified aviation safety officers are determined, and the questionnaire of psychological quality of aviation safety officers is designed. Then the structural equation model is used to determine the weight of each index, which provides a reference for the research of psychological quality of aviation safety officers; based on the analysis of the task characteristics, qualification standards and job description of civil aviation maintenance personnel, literature [4] extracts the competency elements of civil aviation maintenance personnel, compiles the competency questionnaire, and verifies it with structural equation model, so as to provide reference for the recruitment and training of civil aviation maintenance personnel.

Although we know from the literature that the research on the safety accident theory has spread to all walks of life, there are few researches on the safety quality and training index of the maintenance personnel. This paper hopes to establish a set of safety quality training index system for maintenance personnel based on the actual situation of the army, and provide some methods and suggestions for post training, ability and quality improvement, safety quality assessment of maintenance personnel. Therefore, based on a large number of data, this paper investigates the basic situation of the safety quality of the maintenance personnel by using the questionnaire survey method, initially defines the composition of the safety quality of the maintenance personnel, analyzes the reliability of the questionnaire content by using SPSSAU system,

ae-mail: fighting_mmx@163.com be-mail: 1312887589@qq.com ${ }^{*}{ }^{*}$ e-mail: wuboy0210@163.com de-mail: a1062392006@163.com e-mail: 510886690qq.com fe-mail: 1796544155@qq.com 
summarizes the components of the safety quality of the maintenance personnel according to the feedback results of the questionnaire, and divides the training indicators; then use Delphi method and analytic hierarchy process to calculate the weight of each training index of maintenance personnel safety quality, find out the key factors, achieve the purpose of key training for maintenance personnel, finally establish the maintenance personnel safety quality training index system, and give suggestions on the safety quality assessment and improvement of maintenance personnel, so that aviation safety can be effectively guaranteed.

\section{SAFETY QUALITY AND FLIGHT SAFETY QUALITY}

Safety quality refers to the intersection of people's safety knowledge, safety skills and safety will. It refers to personnel's judgment of their own situation in an emergency and their ability to use safety knowledge and skills to protect themselves and others in handling accidents. Personnel working in aviation maintenance posts should also have the quality of maintenance safety. The so-called "maintenance safety quality", in my opinion, is "the quality that the maintenance personnel should have when engaged in the maintenance work and various supporting tasks, should include: good physical quality, healthy psychological quality, excellent professional quality and comprehensive ability quality, etc. These qualities not only require a certain period of training and exercise before taking the post, but also require the maintenance staff to be serious and dedicated, good at summarizing and modestly learning when engaged in the maintenance work. Only in this way can the quality of the maintenance staff be effectively improved and better serve the aviation unit.

\section{ANALYTIC HIERARCHY PROCESS (AHP)}

\subsection{Overview of the analytic hierarchy process}

Analytic Hierarchy Process (AHP) is a hierarchical weight decision-making method proposed by Satie, an American operations researcher, in the early 1970 s by integrating network system theory and multi-objective evaluation method. It is a multi-objective decision analysis method that combines qualitative and quantitative analysis methods. The main ideas of the law by the complex problem is decomposed into several layers and several factors, for two important degree between the two indicators make comparative judgment, to establish judgment matrix, calculated largest eigenvalues and corresponding eigenvectors of judgment matrix, can give different weights of importance degree, offer the decision basis for the selection of the best solution.

Analytic Hierarchy Process (AHP) is often used in the field of safety science and environmental science. By establishing hierarchical structure model and calculating weight index, it can guide the final decision of practical problems and seek the best solution.

The main purpose of this article used analytic hierarchy process (ahp) is, for crew safety quality training of the main factors of index weight calculation, verify whether it conforms to the consistency check, namely the consistency of the verification, the result of the questionnaire for the final index system of Air Force air crew safety quality training research each index provides data support.

\subsection{Basic steps of the analytic hierarchy process}

(1) Establishment of hierarchical structure model. The basic practical problems and needs, the decision-making objectives, criteria, objects and their mutual relations are divided into target layer, criterion layer and scheme layer. The number of levels in the hierarchy depends on the complexity of the problem and the detail of the problem analysis. The number of levels is generally unlimited, but the number of elements in each level should not be more than 9 .

(2) Constructing all judgment (paired comparison) matrices. In order to improve the accuracy of weight determination, all comparative factors are not put together for comparison, but pairwise comparison is adopted to better evaluate the importance degree of factors with different natures. Satie cites the numbers 1-9 and their reciprocal as scales. The scale table is shown in Figure 1.

\begin{tabular}{lc}
\hline scale & meaning \\
\hline 1 & It means that the two factors are of equal importance compared to each other \\
3 & It indicates that the former is slightly more important than the latter \\
5 & Compared with the two factors,the former is obviously more important than the latter \\
7 & It indicates that the former is more important than the latter \\
9 & Compared with the two factors,the former is more important than the latter \\
$2,4,6,8$ & Represents the median value of the above adjacent judgements \\
The bottom & If the importance radio of factor $\mathrm{i}$ to factor $\mathrm{j}$ is,then the importance ratio of factor $\mathrm{j}$ \\
factor $\mathrm{i}$ is $a_{j i}=1 / a_{i j}$
\end{tabular}

Fig1. Schematic diagram of risk matrix

(3) Single hierarchical sorting and consistency test. The consistency test of judgment matrix is needed for the accuracy of single hierarchical ordering. If and only if $\lambda=n, \mathrm{~A}$ is the consistency matrix.

The steps of consistency testing are divided into three steps:

Firstly, the consistency index CI was calculated. $C I=\frac{\lambda-n}{n-1}$ When $C I=0$, there is complete consistency; when CI approaches 0 , the consistency is satisfactory; the larger the CI, the worse the consistency.

The second is to find the random consistency index Ri, $R I=\frac{C I_{1}+C I_{1}+\cdots+C I_{1}}{n}$ and $\mathrm{Ri}$ is related to the order $\mathrm{n}$ of the judgment matrix. In general, the larger $\mathrm{n}$ is, the higher the consistency is. The standard value of the average random consistency index is shown in Fig.2

\begin{tabular}{ccccccccccccccc}
\hline $\mathrm{n}$ & 1 & 2 & 3 & 4 & 5 & 6 & 7 & 8 & 9 & 10 & 11 & 12 & 13 & 14 \\
\hline $\mathrm{RI}$ & 0 & 0 & 0.52 & 0.89 & 1.12 & 1.24 & 1.36 & 1.41 & 1.46 & 1.49 & 1.52 & 1.54 & 1.56 & 1.58 \\
\hline
\end{tabular}

Fig2. Standard value of average random consistency index

In general, $C R=\frac{C I}{R I}$ when, it is considered that the consistency of $C R<0.1$ the judgment matrix meets the requirements; otherwise, it is necessary to modify the judgment matrix.

(4) Hierarchy sorting and consistency test. The 
combined weight of the elements in a certain level relative to the overall goal is calculated by using the single ranking result of all levels in a certain level, and the ranking is carried out from top to bottom until the elements in the scheme level are sorted.

\section{CREW SAFETY CONSTRUCTION QUALITY INDEX SYSTEM OF TRAINING}

\subsection{Principles of index system construction}

(1) Systemic principles. The selected indexes are logically related and interrelated, and reflect the theme content of the index system from different aspects. All the indicators constitute a system, and each indicator is a representative subsystem of some aspect of the system.

(2) The principle of typicality. Making sure that the selected indicators are typical -- each indicator can describe a certain aspect of the system as accurately as possible and is an indispensable part of the system.

(3) the principle of purpose. Each indicator in the selection should closely around the central theme of the system, starting from the research problem, from the purpose and effect we want to achieve, goal-oriented, select the required indicators.

(4) Principle of comprehensiveness and independence. The principle of comprehensiveness refers to the consideration and screening of all aspects related to the topic in the selection of indicators, so as not to omit any aspect in the selection of indicators. In the selection of indicators to ensure comprehensiveness at the same time, we should also pay attention to the independence of the indicators, that is, the selected indicators should try to avoid content overlap too much, too close intersection. If the cross content of the index is too much, it will lead to the construction of a chaotic system, the point of view is difficult to distinguish; if the selected indicators are too independent, the internal connection between the system will appear not close enough. The relationship between comprehensiveness and independence when selecting indicators is shown in Figure 3.

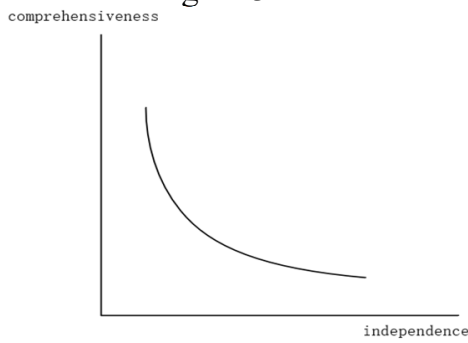

Fig3. Relationship between comprehensiveness of index selection and independence

(5) Feasibility principle. That is, the selected system index is easy to obtain data or easy to verify, is in line with the real situation, can get effective data to support and explain it.

\subsection{Questionnaire}

- Basic contents of the questionnaire

This paper issued questionnaires twice to collect data.
The main contents of the questionnaires are as follows:

The first questionnaire is an open question questionnaire, consisting of 7 questions, mainly investigating the understanding and cognition degree of the safety quality of the aircraft crew.

The second questionnaire was a closed question questionnaire, including 27 selective propositions, which mainly included the following two parts:

(1) Basic information: including gender, age, major, position, time engaged in maintenance work, education level, marriage and other 7 parts.

(2) Quality survey: it mainly investigates the basic situation of safety quality of maintenance personnel, which is the subject part of this questionnaire. There are altogether 20 questions, including four aspects of physical condition, psychological condition, professional quality and safety ability quality.

- Reliability and validity analysis of the questionnaire

After the questionnaires were distributed, a total of 120 valid questionnaires were collected, and the reliability and validity of the 120 questionnaires were analyzed to test the reliability of the questionnaires.

(1) Reliability analysis

Questionnaire credibility refers to the degree of consistency or stability of questionnaire survey results. The reliability analysis methods used in this paper include the half-fold coefficient analysis method and the Kronbach coefficient reliability analysis method, and the reliability analysis is carried out using SPSSAU system. Cronbach's $\alpha$ Generally speaking, when the reliability coefficient is higher than 0.8 , it indicates a high reliability. Anything below 0.6 indicates that the reliability is unacceptable and requires a new investigation.

Through the odd-even classification of 20 questions in the "quality survey" module, and the analysis of equilength halves is carried out. The analysis results are shown in Table I below.

TableI. Analysis results of half coefficient

\begin{tabular}{|c|c|c|l|}
\hline \multirow{3}{*}{ Fold half reliability analysis } \\
\hline \multirow{3}{*}{ Cronbach's $\alpha$ coefficient } & \multirow{2}{*}{ The first half } & value & 0.660 \\
\cline { 2 - 4 } & In the second part & A number of & 10 \\
\cline { 2 - 4 } & & value & 0.313 \\
\cline { 2 - 4 } & The total number of & 10 \\
\hline The value of the phase relation between the front and rear halves & 20 \\
\hline \multirow{2}{*}{$\begin{array}{c}\text { Fraction coefficient } \\
\text { (Spearman-Brown coefficient) }\end{array}$} & \multicolumn{2}{|c|}{ isometric } & 0.792 \\
\cline { 2 - 4 } & Before long & 0.884 \\
\hline \multicolumn{2}{|c|}{ Guttman Split - Half coefficient } & 0.832 \\
\hline
\end{tabular}

According to the analysis results, Spearman-Brown coefficient was 0.884 , greater than 0.8 , indicating a high consistency among the measurement items of the questionnaire content, which could be used for further data analysis.

After the correlation analysis of 20 survey questions in the module of "Quality Survey", Cronbach reliability analysis was carried out for 17 questions with strong overall correlation. The analysis results are shown in Table II. 
TableII. Cronbach reliability analysis results

\begin{tabular}{|c|c|c|}
\hline \multicolumn{3}{|c|}{ Cronbach reliability analysis - simplified format } \\
\hline \multirow{2}{*}{ number of items } & sample size & Cronbach's $\alpha$ coefficient \\
\hline 17 & 31 & 0.825 \\
\hline
\end{tabular}

According to the analysis results, the Cronbach's $\alpha$ coefficient is 0.825 , greater than 0.8 , indicating that the reliability quality of the research data obtained from the questionnaire is high, and it is suitable for the questionnaire research.

(2) Validity analysis

Validity usually refers to the accuracy of the measurement results and the extent to which the questionnaire can reflect the theoretical concepts it measures. The content validity and structure validity of the questionnaire were analyzed in this paper. Content validity analysis refers to the degree to which the content of the questionnaire fits the purpose of the survey. It is mainly analyzed by logical inference method and expert evaluation method. Structural validity refers to the corresponding relationship between measurement results and design theory index dimensions. Generally, exploratory factor analysis is used to calculate $\mathrm{KMO}$ (Kaiser-Meyer-Olkin) index and Bartlett's $\mathrm{P}$ value of spherical degree test. Usually, KMO is greater than 0.8 , indicating high validity; between $0.8-0.7$, the validity is good; less than 0.6, the validity is not good. Bartlett sphericity test $\mathrm{P}$ value should be less than 0.05 to indicate validity.

In the process of designing the questionnaire, this paper referred to a large number of questionnaire scales related to safety quality, and modified the contents by combining expert opinions, which has a high content validity. In structural validity analysis, factor analysis is mainly adopted, and SPSSAU system is used for data analysis. The analysis results are shown in Table III.

TableIII. Test results of KMO and Bartlett

\begin{tabular}{|c|c|c|}
\hline \multicolumn{2}{|c|}{ KMO value } & 0.755 \\
\hline \multirow{3}{*}{ Bartlett's test for sphericity } & The approximate chi-square & 382.431 \\
\cline { 2 - 3 } & $\mathrm{df}$ & 120 \\
\cline { 2 - 3 } & P values & 0.000 \\
\hline
\end{tabular}

As can be seen from the above table, KMO value is 0.755 , greater than 0.6 , which has high validity. Bartlett sphericity test $\mathrm{P}$ value is less than 0.05 , indicating that the questionnaire has structural validity.

\subsection{Determination of safety quality training indexes}

After the feedback of two questionnaire surveys and the induction of the components of safety quality of maintenance personnel, the indicators of safety quality at all levels are divided. The specific division is as follows:

(1) First-level indicators

Through the influence factors of engineering safety accidents, the deep understanding of the "man, machine, ring", according to the flight crew safety and quality and safety accidents the close relationship between, in combination with the practical situation of crew and flight safety, the level of training of Air Force air crew safety quality index is divided into: personal safety quality and professional quality.

(2) Second-level indicators

In the first-level training index, personal safety quality includes: physical quality and psychological quality; professional safety quality includes: professional quality and safety ability quality.

The physical quality of the maintenance personnel directly affects the safety and reliability of the maintenance work.

The psychological quality of the flight crew, such as the management of emotions, resistance to pressure from the outside world, the cognitive degree of the concept of "safe work", is the internal basis to support the safe behavior, and is also the multiplier of the validity of "safe work".

The professional quality of the aircrew refers to: the sense of thinking in big-picture terms; the sense of responsibility to fulfill their duties; the awareness of laws and regulations in accordance with the law; the political consciousness of serving the people; professional dedication of "love what you do " and excellent basic professional knowledge.

The safety ability quality of the maintenance personnel is a comprehensive embodiment of the professional knowledge, work experience and work ability of the maintenance workers.

\subsection{Weight calculation of safety quality training indexes}

The determined safety quality training indexes were handed over to experts, and then the importance of the indexes was determined according to the scale of "1-9". The results are shown in Table IV.

TableIV. Classification table of importance judgment of safety quality training indexes for maintenance personnel

\begin{tabular}{|c|c|c|}
\hline Level indicators & The secondary indicators & Level 3 indicators \\
\hline \multirow{3}{*}{$\begin{array}{c}\text { Personal Safety Quality } \\
\text { B1 (5) }\end{array}$} & \multirow{2}{*}{ Physical fitness B11 (4) } & Strength indicator B111 (5) \\
\cline { 2 - 3 } & & Endurance index B112 (3) \\
\cline { 2 - 3 } & & Sensitive index B113 (3) \\
\cline { 2 - 3 } & & Emotion management ability index B121 (5) \\
\hline
\end{tabular}




\begin{tabular}{|c|c|c|}
\hline & \multirow{4}{*}{$\begin{array}{l}\text { Psychological quality B12 } \\
\text { (6) }\end{array}$} & Stress resistance index B122 (4) \\
\hline & & Cognitive ability index B123 (6) \\
\hline & & Optimism indicator B124 (3) \\
\hline & & Confidence indicator B125 (3) \\
\hline \multirow{9}{*}{$\begin{array}{l}\text { Professional safety } \\
\text { quality B2 (7) }\end{array}$} & \multirow{6}{*}{ Professional quality B21 (7) } & Sense of responsibility index B211 (7) \\
\hline & & Political awareness indicator B212 (5) \\
\hline & & Regulatory Awareness Index B213 (7) \\
\hline & & Big-picture awareness indicator B214 (3) \\
\hline & & professional dedication Index B215 (4) \\
\hline & & basic Professional knowledge index B216 (9) \\
\hline & \multirow{3}{*}{$\begin{array}{l}\text { Safety competence quality } \\
\text { B22 (5) }\end{array}$} & $\begin{array}{c}\text { Professional and Technical Capability Index } \\
\text { B221 (7) }\end{array}$ \\
\hline & & Risk identification ability index B222 (4) \\
\hline & & Emergency response capacity index B223 (5) \\
\hline
\end{tabular}

Then the analytic hierarchy process was applied to construct a judgment matrix combined with the safety quality training indexes, and the weight of each training index was calculated. The results were shown in the table below.

TableV. Weight distribution of safety quality training indexes for Air Force aviation crew

\begin{tabular}{|c|c|c|c|c|c|c|c|}
\hline \multirow{20}{*}{$\begin{array}{l}\text { Safety } \\
\text { quality } \\
\text { training } \\
\text { index } \\
\text { system of } \\
\text { Air Force } \\
\text { aviation } \\
\text { crew }\end{array}$} & \multirow{3}{*}{$\begin{array}{l}\text { Level } 1 \\
\text { indicators }\end{array}$} & \multirow{3}{*}{$\begin{array}{c}\text { Level } 3 \\
\text { indicators }\end{array}$} & \multicolumn{4}{|c|}{ The secondary indicators } & \multirow{3}{*}{$\begin{array}{l}\text { The weight } \\
\text { ratio of the } \\
\text { three-level } \\
\text { indicators to } \\
\text { the whole }\end{array}$} \\
\hline & & & B11 & $\mathrm{B} 12$ & $\mathrm{~B} 21$ & $\mathrm{~B} 22$ & \\
\hline & & & 0.400 & 0.600 & 0.548 & 0.416 & \\
\hline & & B111 & 0.454 & 0 & 0 & 0 & 0.0755456 \\
\hline & & B112 & 0.273 & 0 & 0 & 0 & 0.0454272 \\
\hline & & B113 & 0.273 & 0 & 0 & 0 & 0.0454272 \\
\hline & B1 & B121 & 0 & 0.238 & 0 & 0 & 0.0594048 \\
\hline & $(0.416)$ & B122 & 0 & 0.190 & 0 & 0 & 0.0474240 \\
\hline & & B123 & 0 & 0.286 & 0 & 0 & 0.0713856 \\
\hline & & B124 & 0 & 0.143 & 0 & 0 & 0.0356928 \\
\hline & & B125 & 0 & 0.143 & 0 & 0 & 0.0356928 \\
\hline & & B211 & 0 & 0 & 0.200 & 0 & 0.0600608 \\
\hline & & B212 & 0 & 0 & 0.143 & 0 & 0.0429435 \\
\hline & & B213 & 0 & 0 & 0.200 & 0 & 0.0600608 \\
\hline & & B214 & 0 & 0 & 0.086 & 0 & 0.0258261 \\
\hline & B2 & B215 & 0 & 0 & 0.114 & 0 & 0.0432438 \\
\hline & & B216 & 0 & 0 & 0.257 & 0 & 0.0771781 \\
\hline & & B221 & 0 & 0 & 0 & 0.467 & 0.1064611 \\
\hline & & B222 & 0 & 0 & 0 & 0.199 & 0.0453656 \\
\hline & & B223 & 0 & 0 & 0 & 0.334 & 0.0761413 \\
\hline
\end{tabular}

\subsection{To establish a safety quality training index system for Air Force aviation crew}

After the weight of each index is calculated by the analytic hierarchy process (AHP), the final index system of safety quality training for aviation flight attendants is established as shown below in Figure 4. 


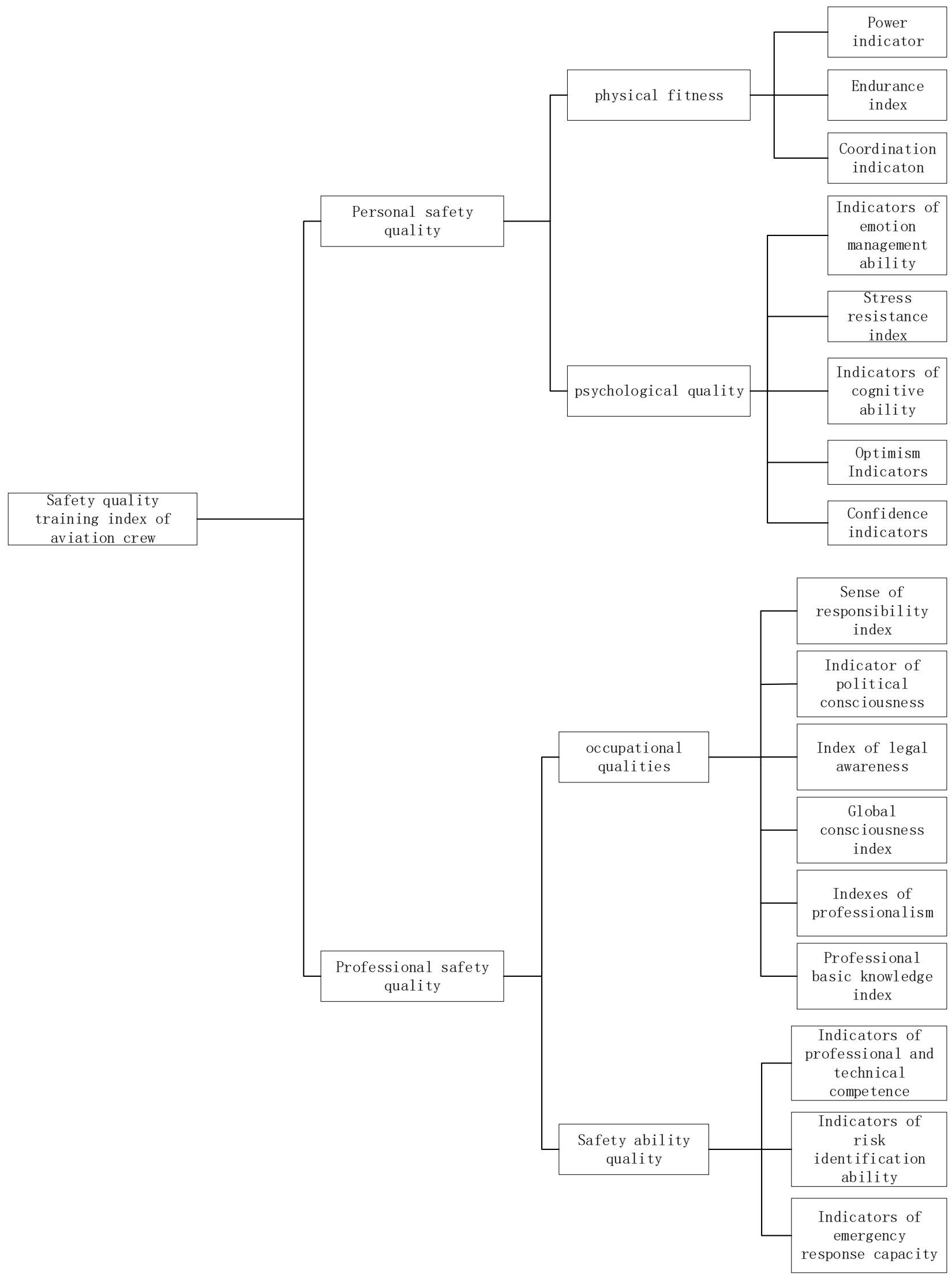

Fig4. Safety quality training index system of Air Force aviation crew

\subsection{Advise on the improvement and assessment} of personnel safety quality

According to the results of the two questionnaire surveys and the weight calculation of each training index, the following suggestions can be put forward from the aspects of quality improvement and professional ability assessment:

(1) Physical quality: individuals should consciously exercise after work to ensure their physical fitness above the qualified level; the unit should appropriately increase 
the physical training time of maintenance personnel to enhance the physical quality of personnel; regularly organize physical assessment and urge personnel to take the initiative to carry out physical training by means of supervision.

(2) Psychological quality: individuals should give vent to their negative emotions and pressure reasonably in time, find suitable ways to adjust their psychological state, and enhance their ability to manage their own emotions; the unit should find the personnel in a bad state in time, and timely understand the situation, "the remedy to the case", help the crew to maintain a good psychological state; carry out mental health education regularly, carry out heart-toheart study work in an orderly way.

(3) Professional quality: individuals should strengthen the study of professional knowledge, develop excellent skills, and strive to improve their professional quality; the unit should strictly pre-job training, special person to teach the system, strengthen the personnel professional spirit, the overall situation of the consciousness of training; professional knowledge and skill competitions can be organized to improve everyone's professional ability.

(4) Safety competence and quality: individuals should strengthen self-learning in daily maintenance work, be good at observation, exploration and summary, and convert tangible knowledge into internal competence and quality; the unit pays attention to the task completion rate at the same time, also should focus on the enhancement of the quality of maintenance personnel, improve the ability of personnel to deal with affairs.

\section{CONCLUSION}

Starting from the background of the times, this paper briefly analyzes the connotation of safety quality and maintenance safety quality, uses the method of questionnaire survey to design questions and collect data, summarizes the "maintenance safety quality", calculates the index weight combined with analytic hierarchy process, and finally constructs the Air Force aviation maintenance personnel safety quality training index system, which is the first in the field of Air Force aviation maintenance. It provides ideas for improving the safety quality of maintenance personnel, provides reference standards for assessing the safety quality of maintenance personnel, and further ensures flight safety. In the later stage, we hope to continuously improve and refine the index system, and on this basis, establish the safety quality training system for Air Force aviation maintenance personnel, so as to train the safety quality of maintenance personnel, and provide support for improving the combat effectiveness of the army while ensuring safety.

\section{ACKNOWLEDGMENT}

First of all, I would like to thank Professor Wu Jun for his careful guidance and concern in my daily life. It is because of the teacher's constant encouragement and enlightenment that I can successfully complete this article. Secondly, I would like to thank all the evaluation experts of the evaluation committee for their valuable suggestions in their busy schedule. Finally, I would like to thank all the students for their help to me. It is with your support and encouragement that I go forward courageously. Thank you!

\section{REFERNENCES}

1. LI Jin. Research on Influencing Factors of Work Stress of Chinese Civil Aviation Pilots [D]. University of International Business and Economics,2019.

2. Zheng Hongli, Peng Hongdi, Xu Xiaoxia.Safety behavior formation of aviation flight attendants $[\mathrm{J}]$. Science and Technology Vision,2013(13):84+103.

3. Wang Yanqing, Zhang Sijia.Journal of Safety and Environment,2018,18(02):623-627.

4. GAO Yang, LI Xiaoxu. Research on Competency Model of Civil Aviation Maintenance Personnel [J]. Safety and Environmental Engineering,2016,23(01):168-172.

5. Guo Jinyu, Zhang Zhongbin, Sun Qingyun. Research and Application of Analytic Hierarchy Process [J].China Safety Science Journal, 2008, 18(5):148153.

6. Deng Xue, Li Jiaming, Zeng Haojian, Chen Junyang, Zhao Junfeng.Analysis and Application of Analytic Hierarchy Process Weight Calculation Method [J]. Mathematics in Practice and Theory,2012,42(07):93100 .

7. Guo Jinyu, Zhang Zhongbin, Sun Qingyun. Research and Application of Analytic Hierarchy Process [J].China Safety Science Journal, 2008, 18(5):148153

8. LUO Yun. Safety Behavior Science [M]. Beijing: Beijing University of Aeronautics and Astronautics Press, 2012:68,69

9. LI Xiaoxu. Research on the Capability of Civil Aviation Flight Personnel [D]. Civil Aviation University of China,2016. 